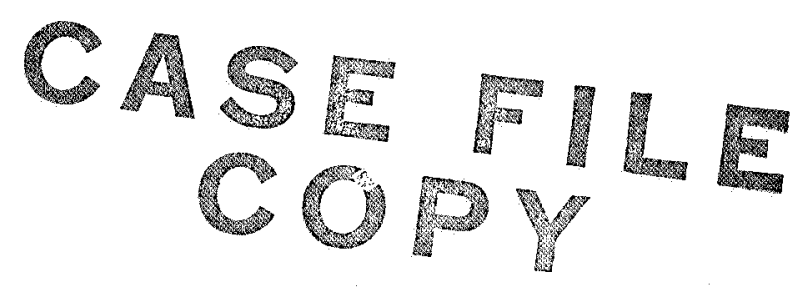

\title{
A REVIEW OF LIFT FAN PROPULSION SYSTEMS FOR CIVIL VTOL TRANSPORTS
}

by S. Lieblein

Lewis Research Center

Cleveland, Ohio

TECHNICAL PAPER proposed for presentation at Sixth

1. Propulsion Joint Specialists Conference sponsored by the American Institute of Aeronautics and Astronautics San Diego, California, June 15-19, 1970 
A REVIEW OF LIFT FAN PROPULSION SYSTEMS

FOR CIVIL VTOL TRANSPORTS

by S. Lieblein

Lewis Research Center

Cleveland, Ohio

TECHNICAL PAPER proposed for presentation at

Sixth Propulsion Joint Specialists Conference

sponsored by the American Institute of Aeronautics and Astronautics

San Diego, California, June 15-19, 1970

NATIONAL AERONAUTICS AND SPACE ADMINISTRATION 


\title{
A REVIEW OF LIFT FAN PROPULSION SYSTEMS
}

\section{FOR CIVIL VTOL TRANSPORTS}

\author{
by S. Lieblein \\ Lewis Research Center \\ National Aeronautics and Space Administration \\ Cleveland, Ohio
}

\section{INTRODUCTION}

Vertical take-off and landing aircraft are currently under study as a means for improving short-haul intercity air transportation systems. VTOL can relieve airport congestion and reduce air time delays, and can also supply access to communities currently without air transportation. VTOL proposes to accomplish these objectives through the use of new terminal sites (e.g., small airports located close to business and population centers) as well as terminal sites at existing airports. Also implied is the use of terminal area air traffic control procedures independent of conventional aircraft.

The feasibility of VTOL intercity air transportation systems has been explored by a number of domestic and foreign organizations and government agencies. It is recognized that there are many aspects to the problem of a VTOL transportation system - economic, sociological, and political, as well as technological. Examples of recent thinking on these aspects are found in Refs. 1 to 7. A total systems approach is undoubtedly required for the successful development of commercial VTOL.

A number of VTOL transport designs for intercity service have recently been studied in this country and abroad. These studies (e.g., Refs. 2 and 8 to 13) were based on various aircraft configurations and various means of providing vertical lift (e.g., rotors, tilting propellers, and high-bypass-ratio lift fans). In general, an overall impression is obtained that there currently is no outstandingly superior aircraft configuration or lift propulsion concept for the civilian VTOL mission, but, given adequate time and resources, a suitable transport aircraft could be developed.

Although there may be differences in opinion concerning the relative "readiness" for the development of VTOL intercity transports, it appears 
safe to state that there would be unanimous agreement that more research and development is desirable on propulsion systems for these aircraft. The general need for such research is motivated by a number of factors: (1) the large number of complex and frequently conflicting requirements placed on these systems; (2) the relatively large number of propulsion concepts potentially usable for this application; and, (3) the critical impact of propulsion system characteristics on aircraft and overall system design and operation. Complete design and performance data and fully optimized technology are currently unavailable for the major candidate propulsion systems. What is needed is a good match between propulsion requirements and system capability.

The propulsion system of a VTOL transport aircraft is required to serve four functions: to provide thrust for vertical lift during takeoff, hover, and landing; to provide horizontal acceleration and deceleration as well as vertical thrust during the transition from vertical to horizontal flight; to provide horizontal thrust during the wing-supported (cruise) portion of the flight; and to provide thrust for control of the aircraft attitude during the takeoff, landing, and transition flight modes. The crux of the aircraft design is to obtain an optimum integration of the four propulsion functions into the aircraft.

The paper considers the low-pressure ratio lift fan propulsion system for intercity VTOL transports. The selection of the lift fan system for vertical lift was based on several features, compared to other thruster concepts, that were considered desirable for civilian transport application. These are: (1) good potential for meeting reduced noise limitations; (2) provision for safe management of failure of power plant or thruster; (3) good passenger and airline appeal for resulting aircraft; (4) capability of high cruise speed approaching that of conventional jet liners; (5) direct use of available gas turbine technology; and, (6) elimination of mechanical transmissions.

The objective of the paper is to review the requirements and problem areas involved in the lift fan propulsion system, and discuss research considerations and approaches aimed at providing the design and performance data necessary for a realistic evaluation of the potential applicability of the 
system for use in VTOL transport aircraft. The first part discusses propulsion functions and concepts for lift, cruise, transition, and attitude control and their interactions. Included is a description of various methods for driving the lift fan, and a discussion of their principal features. The second part of the paper deals with the major design requirements of the lift fan system. This section reviews major considerations in installed fan characteristics such as thrust, noise, weight, and component and system design. Factors in fan transition performance are also summarized. Desirable research efforts are identified throughout.

\section{LIFT FAN SYSTEMS}

With the adoption of the low-pressure-ratio fan stage as the basic thrust device for vertical lift, it now must be decided how the fan rotor is to be powered. The various types of fan systems will first be described, followed by a discussion of their principal features and potential advantages and disadvantages.

\section{Types}

Fan systems are identified by the type of turbine used to drive the fan rotor and by the relationship between the fan and the powerplant supplying power to the fan drive turbine. Two general types are currently recognized, the integral power system and the remote power system. An isometric drawing of the principal arrangements for these two systems is shown in Fig. 1 without inlet sections for the fans or powerplants.

The integral coaxial system (Fig. 1(a)) is similar to a high-bypassratio turbofan in which the fan is powered by a coaxially-mounted gas turbine engine. A schematic cross section of a possible configuration for a coaxial drive lift fan system is shown in Fig. 2 to illustrate some design details. In this approach, a folded combustor and reduced compressor pressure ratio is used to reduce the axial depth of the powerplant. The cross-hatched sections in the fan duct indicate acoustic treatment. This type of lift fan has been promoted by Rolls Royce Ltd. 14 to 19 and Pratt and Whitney Company ${ }^{20}$.

In the remote type (Figs. 1(b), (c), and (d)), the fan and its drive turbine are separately located from the powerplant, and power is delivered 
pneumatically to the fan drive turbine. The remote power concept can employ a turbine drive for the fan rotor located either on the outer periphery of the fan (tip turbine drive) as shown in Figs. 1(b) and (c), or coaxially with the hub of the fan as shown in Fig. 1(d). For the remote systems, the drive turbine can be supplied either by the exhaust from a hot gas generator (Fig. 1(b)), or by high-pressure air from a compressed-air generator (Figs. 1(c) and (d)). In the latter case, an option exists to deliver the compressed supply air directly to the fan turbine, or to raise it to a high temperature in an auxilliary combustor at the fan before delivery to the drive turbine.

A schematic cross section of a lift fan with a tip turbine drive is shown in Fig. 3(a). The fan design involves a single wheel which carries the fan rotor blades and the tip turbine buckets mounted around the periphery of the fan. Also shown is the scroll which feeds the hot gas to the turbine nozzles. Figure $3(b)$ shows a schematic cross section of a straight turbojet exhaust gas generator that could be used to drive the tip turbine fan. The tip turbine fan driven by an exhaust gas generator has received considerable attention by the General Electric Company 21 to 26 . This is the fan arrangement used in the XV-5A VTOL aircraft ${ }^{27}$.

For advanced gas generator systems, increased exhaust temperatures may cause difficulties in the design of the fan turbine scroll. Accordingly, it may be desirable to consider a gas generator with a low bypass ratio, as shown in Fig. 3(c), in order to provide for some lower-temperature air that could be used for cooling purposes. The bypass air can be bled off directly behind the low spool (configuration $\mathrm{A}$ ), or mixed with the core exhaust (configuration $\mathrm{B}$ ), or allowed to flow coaxially with the discharge duct (configuration $\mathrm{C}$ ).

A schematic cross section of a tip turbine driven lift fan based on a compressed air generator (Fig. 1(c)) is shown in Fig. 4(a). The principal difference between this configuration and the configuration for the exhaust gas generator power supply (Fig. 3(a)) is a two-stage turbine and a smaller scroll diameter. Both of these are the result of the higher fan turbine inlet pressure levels provided by the compressed air supply. 
Figure 4(b) illustrates the details of a hub-drive fan concept that can beused in conjunction with a remote compressed air generator (Fig. 1(d)). In this arrangement, high-pressure air is delivered to a combustor and conventional drive turbine located coaxially with the hub of the fan. Compressed air for the combustor is delivered through struts across the fan flow passage (possibly stator-struts as shown) from an outer feed scroll. An inner flow distribution to the combustor must also be provided.

A schematic cross section of a compressed air generator concept is shown in Fig. 4(c). In this configuration the low compressor is designed to provide the required pressure for the supply flow to the fan turbine. Again, a folded combustor is shown to reduce axial length. The residual thrust from the core discharge can be used to provide vertical thrust, or in conjunction with a swivel nozzle, can be used to provide vectored thrust during transition.

For situations in which relatively large amounts of emergency overthrust capability are required (e.g., interconnected system with few air generators and larger number of fans), an interburner can be added between the high compressor drive turbine and low compressor drive turbine of the two-spool configuration shown in Fig. 4(c). However, it is not clear whether the addition of such a capability in this manner warrants the added complexity of another fuel system and additional flow pressure drop when the unit is in normal operation.

\section{Features}

Now that the general physical characteristics of the lift fan power systems have been established, it remains to evaluate their relative merits and deficiencies. Figure 5 lists a summary of the major advantages and disadvantages recognized for the four fan systems of Fig. 1. Advantages are listed first, with disadvantages numerated below. A basically qualitative elaboration of some of these features will now be presented.

Integral system. - The principal virtue of the coaxial lift fan concept (Fig. 1(a)) is the inherent simplicity of working with self-contained independent units. This provides a simple reliable means for supplying safety through redundancy in the event of a shutdown of either a powerplant or a 
fan. Single units can also simplify the propulsion installation in some aircraft configurations. In addition, no basically new component concepts or technology are required. There also exists a good potential for providing a significant capability for contingency overthrust in the event of emergency situations through short-time overspeed and overtemperature operation.

On the debit side, the relatively long axial depth of the coaxial fan may restrict the aircraft locations in which the fan can be installed, and may require deep pods with significant weight and drag penalties. In this configuration, the flow into the core compressor is also subject to crossflow distortion effects during transition which might compromise the design of the gas generator. Finally, with the diameter of the fan drive turbine considerably smaller than that of the fan rotor, many turbine stages are required. This makes the turbine long and heavy, so that turbine length and weight will be very sensitive to the tip speed of the fan rotor.

The required number of turbine stages and overall axial length, of course, can be reduced if reduction gearing is used for the fan rotor. However, this approach would require the development of high-power-level gearing that would be both compact and light in weight. Although it is clear that reduction gearing would decrease axial length and consequently improve the installation situation, its effect on overall fan system weight and operating reliability and maintainability is uncertain.

Remote systems. - Tip-turbine driven lift fans of the remote systems (Figs. 3(a) and 4(a)) have the potential for providing a substantially shorter axial depth than the hub-turbine driven fans (Figs. 2 and 4(b))。 Greater installation flexibility may therefore be achieved for the aircraft (e.g., more suitable for fuselage contained or fold-out arrangements). However, it is not clear at this time whether this short depth potential can be fully realized because of the uncertainty in the amount of acoustically-treated duct length that might be required to satisfy perceived noise limitations. This factor will be discussed in a later section.

One of the principal features of the remote fan systems (Figs。3 and 4) is the potential for powerplant interconnecting. Powerplant interconnection can permit shutdown of a powerplant without total loss of thrust of the corresponding fan (as is the case with independent units), and can allow for fewer 
powerplants than fans. Pneumatic interconnecting can also readily provide for the use of the powerplant system to power auxiliary attitude control fans and cruise fans, if used. In all cases, however, appropriate valving and controls will be required for proper system operation and reliability (e.g. , start up, powerplant shutdown, and fan shutdown). Powerplant interconnecting is based on the consideration that a failure of a powerplant is more probable than the failure of a fan.

With an interconnected system, the shutdown of one of the powerplants driving a number of fans causes a decrease in fan speed and pressure ratio. As fan pressure ratio is reduced, the ratio of input power to delivered thrust is also reduced for fans with good off-design efficienty characteristics. Thus, the loss of a fraction of the supply power results in a proportionately smaller loss in total fan thrust. For the independent fan systems, the fractional loss in total fan thrust is directly proportional to the fractional loss in power.

The remote fan systems contain two separate elements (fan and powerplant) with different orientations for their axes. It is not clear whether this will have an adverse or beneficial effect on aircraft installation and component accessibility and cost. Furthermore, remote systems may require closure doors for the powerplants as well as the lift fans during cruise flight.

The principal consideration in favor of the remote exhaust gas generator system is the existence of available gas generator engine technology and tipturbine fan design experience. These can provide for a relatively early flight aircraft application. However, if the high exhaust temperatures of advanced turbojet gas generators are accepted, scroll and tip turbine construction, cost, reliability, and limited overtemperature capability for emergency overthrust can be liability factors. This difficulty can be relieved to some extent with the use of a low-bypass-ratio gas generator as in Fig. 3(c). Engine technology is also relatively a vailable for this approach.

Tip-turbine fans can be used either in an independent close-coupled configuration as illustrated in Fig. 1(b) or with interconnected gas generators. However, this latter arrangement may require the use of relatively hightemperature valving and large-diameter high-temperature ducting, which may be undesirable in a civilian passenger transport. 
Air generator systems. - The thermodynamic aspects of the use of a compressed air generator to supply power to drive the lift fan (Fig. 1(c)) are illustrated in Fig. 6. Figure 6(a) shows the variation of required gas flow rate to the fan tip-turbine with total pressure at the inlet to the fan turbine combustor for a two-stage turbine. The calculations were made for a tip-turbine-drive lift fan producing a total thrust of 10000 pounds at a fan pressure ratio of 1.2 and rotor tip speed of $815 \mathrm{ft} / \mathrm{sec}$. Turbine inlet temperature is included as a parameter. The curve for air generator with a single stage tip turbine represents the case without fan combustor (cold supply case). For comparison, the gas flow rate required for a single-stage tip turbine powered by an exhaust gas generator is indicated by the symbol points.

The reduction in required turbine flow rate with increasing supply pressure and temperature is quite marked. Considerable reduction in scroll diameter and turbine blade height are therefore indicated with the compressed air generator due to the combined effects of high supply pressure and reduced flow rate. The higher pressure level in conjunction with a controlled inlet temperature with the use of a combustor at the fan provide the capability for an easier and lighter scroll design. However, values of supply temperature above around $1900^{\circ}$ to $2100^{\circ} \mathrm{R}$ will raise the cooling requirement and design complexity.

On the debit side, the two-stage, short-blade-height tip turbine introduces complications of its own with respect to front seal and interstage leakage as well as dimensional distortions. Thus, the principal advantage of the compressed-air generator systems, aside from the improved tip turbine scroll design situation, is its ability to allow for powerplant interconnecting with low temperature, small diameter ducting.

Corresponding variations in air generator ratio of total inlet airflow to delivered compressed airflow and specific discharge thrust are shown in Fig. 6(b). Discharge thrust was computed for a fixed exhaust velocity around 20 percent greater than the fan exhaust velocity. The trends in Fig. 6 can therefore be used to obtain an indication of the relative sizes of the fan turbine scroll and the powerplants for the two types of supply flow generators. It can be determined from these results that the frontal area of a compressed 
air generator will be somewhat greater than that of the exhaust gas generator for gas delivered to the fan at the same temperature. However, the fan tip diameter as well as the overall diameter can be smaller with the air generator approach. There may also be differences in the magnitude of the ram drag generated by the different power systems for a given total vertical thrust.

The penalty in increased air generator size involved in the use of a simple nonburning supply configuration can also be estimated from the curves in Fig. 6. For this case the supply air temperature at the discharge from the generator was found to vary from around $940^{\circ} \mathrm{R}$ at a supply pressure of six atmospheres, to around $1100^{\circ} \mathrm{R}$ at ten atmospheres.

If the use of available engine technology is desired, compressed air in this approach can also be supplied from a compressor driven by a turboshaft engine. Such an arrangement, however, would be longer than the concept of Fig. 4(c) and would require independent inlets for the supply compressor and the powerplant.

A compressed air generator which delivers the high pressure air to a combustor and drive turbine located coaxially with the hub of the fan (Figs. 1 (d) and 4(b) has been considered as a means of avoiding the hot turbine and scroll design problems of the tip turbine approach (Fig. 4(a)) and the compressor inlet distortion situation of the integral coaxial concept (Fig. 2)。 Furthermore, with the use of a conventional coaxial drive turbine arrangement, the approach of Fig. 4(b) allows higher turbine inlet temperatures than with the tip turbine arrangement of Fig. 4(a). The resulting reduction in required turbine flow rate permits the use of a smaller air generator and ducting size. This is of particular importance for interconnected systems. However, this configuration tends to combine the major undesirable features of both powerplant systems (long axial depth and added complexity), and approaches an escalation to nearly two full engine systems for a single fan thruster.

It is thus seen that there are a large number of ways to drive the lift fan - each has its advantages and disadvantages, which will depend on the specific requirements of the propulsion system and the installation approach 
in the aircraft. Comparative evaluations of the different fan drive systems are currently in progress at the NASA Lewis Research Center. The objective of the study is to identify optimum cycle conditions, weight, and dimensional characteristics for the various contending drive systems, as well as potential gain and problem areas for the system components.

\section{TOTAL PROPULSION SYSTEM}

\section{Cruise Thrust}

Thrust for the wing-supported portion of the flight (climb, cruise, descent) can be supplied by conventional cruise engine concepts. Therefore, a vailable cruise engine designs would be adequate. However, cruise engines with moderate bypass ratios (from around 3 to 6 ) although good for optimum cruise performance, may be too noisy at full throttle during the transition part of the VTOL flight because of the magnitude of the exhaust velocity. Thus, it would be necessary to operate such engines at reduced power during transition, such that these engines might not provide sufficient thrust for horizontal acceleration or deceleration. In this event, horizontal thrust during transition would have to be provided by some other means. Furthermore, the full thrust capability of the cruise engines could be not be made a vailable for providing vertical lift during takeoff and landing. However, as will be indicated later, reduced-power cruise engines can also be used to supply attitude control power.

In order to meet noise restrictions, a cruise fan or cruise engine with a relatively high bypass ratio comparable to that of the lift fans would have to be used. However, with a high-bypass-ratio design, it becomes increasingly difficult to provide for downward thrust vectoring to assist during liftoff or for thrust reversing for horizontal deceleration during transition without large weight penalties. Other considerations involved in the use of high-bypass-ratio fans or engines for cruise are the additional drag incurred during cruise and the necessity to design for the proper match between cruise and takeoff settings. Thrust lapse rates become steeper with flight speed as the fan bypass ratio is increased. In any event, the inherent simplicity of using identical lift and cruise fans appears to warrant attention. 
High-speed wind-tunnel tests with lift fan transport aircraft models are indicated to investigate aircraft cruise aerodynamics for the different cruise propulsion approaches. Such model tests can also define the effects of lift fan installations (e.g., pods or fuselage blisters) on cruise performance. Another factor of interest should be ways of utilizing cruise engine exhaust flow to provide aerodynamic lift augmentation (e.g., blown flaps) so that conversion speed can be reduced. Low conversion speeds are desired to reduce flight operating time and fuel consumption for the lift fan system, and also to minimize the effects of fan inlet flow distortion generated by inlet crossflow.

\section{Transition Thrust}

During the transition from vertical to horizontal flight, vertical thrust will be supplied by the lift fans. Horizontal thrust for acceleration or deceleration can be provided in one of the three ways illustrated in Fig. 6. In parts (a) and (b), the main lift fans are used to supply this function. In the first approach, exit louvers are attached to the fixed fan with appropriate deflection capability for forward and rearward thrust vectoring. In the second approach, the entire fan is swivelled fore and aft to provide the required thrust vector. This latter appraoch is more amenable to the integral type of lift fan because of the relative ease with which such a fan can be swiveled. Swiveling with remotely-powered lift:fans would be more difficult because of the problem of providing for a swiveling seal for the drive gas supply. Swiveled fans are expected to have better inflow and outflow characteristics than the louvered fan approach for aft thrust vectoring, but not for forward vectoring. Swiveled fans also require a deeper pod to allow for the swiveling. Additional pod drag will be incurred in the swiveling case compared to the exit louver case because of the poor aerodynamics around the fan installation. On the other hand, there are limits to the travel of fixed-camber louvers because of the excessive vane drag losses incurred as the angles are increased beyond the low-loss points. Ideally, what is desired in this respect is louvers of variable camber. Louvers and their actuating systems provide for a fairly heavy weight addition to the installed fans. 
The lower sketch in Fig. 7 illustrates the use of a cruise fan for supplying horizontal thrust during transition. This can be accomplished either with a fixed fan with provision for thrust deflecting and reversing as shown by the dashed configurations, or by a tilting fan that can be rotated 90 degrees to provide either vertical lift or horizontal thrust. A tilting cruise fan is probably more amenable to a fuselage mounted installation. It might also be possible to obtain required thrust deflecting and reversing with wing flaps in conjunction with fixed cruise fans or engines. The various performance limitations, trade-offs, and installed characteristics of the different thrust modes are presently not well defined.

\section{Control Thrust}

Thrust for the control of aircraft attitude during takeoff, landing, and transition can also be supplied in a number of different ways. If the main lift fans are located off the center of gravity of the aircraft (i.e., in wing or fuselage mounted pods), then control in roll can be obtained by modulating the thrust of the lift fans. Control in pitch can also be obtained by thrust modulation of the main lift fans in the podded arrangement, if the fore and aft fans are located with a sizeable longitudinal separation.

Thrust for yaw control can be readily supplied with exit louvers on the main lift fans in which forward-deflected thrust is supplied on one side of the aircraft and aft-directed thrust on the other side. The same effect can be obtained with fore and aft swiveling lift fans.

If the main lift fans are located within the fuselage of the aircraft such that they are close to the aircraft center of gravity, then fan thrust modulation no longer becomes a useful method for attitude control. In this event, it is required that either the cruise engines be used or auxiliary, low-pressure-. ratio fans be supplied. If moderate bypass ratio cruise engines are used, such that they are operated at low power settings and do not contribute to the horizontal acceleration or deceleration thrust requirement, sufficient power may be available for attitude control in roll, pitch, and yaw. This will require proper location on the aircraft and appropriate thrust deflection devices. However, if the cruise engines are used for attitude control purposes during transition, it is necessary that redundancy be supplied so that 
control power can be maintained in the event of a cruise engine failure.

Auxiliary thrusters for attitude control can be provided by independent low-pressure-ratio fans located fore and aft or at the wing tips. These control fans can be of the self-contained hub drive type, or can be tip-driven fans powered by bleed air from the main cruise or lift engine compressors, or by supply air from interconnected compressed air generators. For the latter approaches, burning can be supplied at the fan periphery to increase turbine power. However, as in the case of cruise engines, it is necessary to supply redundant units to account for failure of any one of the thrusters. For purposes of engine maintenance and installation, it would be desirable to have the auxiliary control fans the same size as the main lift fans. Discussions of attitude control systems are given in Refs. 28 and 29.

High-velocity reaction jets are not considered desirable for commercial VTOL transports because of the associated high noise and high bleed flow rates required.

\section{System Integration}

In view of the large number of approaches possible for the lift, cruise, and control functions, it is not difficult to appreciate the dilemma of the aircraft designer in attempting to select and integrate the various elements of the propulsion system in the aircraft installation. Furthermore, the manner in which the propulsion functions are provided for will exert a substantial influence on the installation of the various propulsion system components as well as the overall configuration for the aircraft. Analysis of the installed characteristics of the two major types of lift fan systems for VTOL transports should provide further information on the relative evaluation of the concepts. In particular, installation thrust losses and weight penalties associated with each of the fan drive systems requires definition. Examples of auxiliary components which contribute to installation weight are thrust deflectors, cover doors for remote power plant inlets during cruise flight, interconnecting ducting, inlets, etc. Furthermore, complete aircraft design studies are desired to explore the optimum integration of all propulsion functions. 
In the experimental area, research is required to explore several key installation questions that can relate to lift system preference. These include: (1) axial length of acoustically-treated duct to suppress fan rotation noise (may negate short depth advantage of tip-turbine remote power concepts); (2) compressor crossflow inlet distortion in the integral coaxial fan concept; (3) thrust deflection aerodynamics and limits for lift and cruise fans; (4) aerodynamic interference effects among propulsion system components; and, (5) cruise drag effects.

\section{LIFT FAN DESIGN}

The design of the lift fan propulsion system to meet desired installed characteristics represents a form of "eternal triangle" with high performance at the apex of the triangle and low noise and low cost at the two lower ends of the triangle. The high performance elements desired for the lift propulsion system are high thrust-to-weight, high thrust-to-volume, low specific fuel consumption, high reliability and maintainability, and low installation losses. These high performance characteristics, which may be in conflict within themselves, are generally not compatible with achieving low noise levels and low cost. Thus, VTOL propulsion system design will be an exercise in compromises and tradeoffs.

Installed Thrust

The design installed thrust of the lift, cruise, and control systems will depend upon the requirements of the specific functions of the systems. In all cases, a knowledge of the aircraft design and mission is required. However, the aircraft design itself will depend upon the installed characteristics of the propulsion system, so that an iterative process is indicated.

The total design installed takeoff thrust for the main lift fans will depend upon a large number of factors such as: aircraft gross weight; vertical thrust contributions of the cruise and attitude control units; amount of fan thrust modulation required for attitude control; design takeoff ambient temperature and altitude; allowable emergency rating in the event of power plant failure; installation losses; desired vertical acceleration with power plant out; the number and arrangement of fans and power plants 
used; and the criteria adopted for "engine-out" safety (e.g., number of units that can fail, powerplant and/or fan failure, or powerplant-only failure). The latter is a matter for airworthiness standards. However, the impact of different safety criteria and provisions on propuls ion system and aircraft design can be quite marked, and should be documented, Furthermore; these effects may not be equal for the different lift fan systems. For civil applications, it is believed that provision should be made for the safe shutdown of a fan as well as a powerplant.

It should be noted that the normal operating thrust (takeoff lift) and the thrust value for which the fan system is noise rated will generally not be the same as the value of installed thrust for which the system is sized. This is illustrated in figure 8 which shows a typical fan operating line. The operating points selected are for the design hot-day, high-altitude takeoff case. Under normal conditions with all units operating, a nominal thrust will be required for lift-off (lower dot), with excursions as needed for control thrust modulation $(\Delta F)_{c, n^{\circ}}$ With a fan or power plant out, an increase in fan thrust will be required to the nominal value indicated by the upper dot. Thrust modulation for control will again be needed $(\Delta F)_{c, o}$, although the value may be somewhat less than that for normal operation. A maximum thrust capability indicated by the uppermost dashed line will therefore be required for safety considerations. If a emergency overthrust capability $(\Delta F)_{E}$ is available, the fan design thrust requirement is reduced to the level of the dot-dash line. Standard sea level installed thrust, of course, will be greater due to the higher corrected speed and ambient pressure. Values of ratio of installed vertical thrust to aircraft gross weight for large VTOL transports are of the order of 1.3 to 1.6 .

Normal fan operation will be at some part-speed point, the magnitude of which will be determined primarily by the installed provisions for "engine-out" safety and total number of fans used. If relatively few fans are used, the normal operating speed may be sufficiently different than the design speed to warrant off-design consideration in the design of the fans. A further research consideration might be the investigation of 
variable-pitch fan rotors to provide for increase in thrust without increase in speed for emergency situations. With this capability, the fan size can be reduced (design for maximum normal thrust). In principle, variable pitch rotors could also be used for rapid-response control thrust modulation.

Noise

For lift fan systems, the principal noise contributors are recognized to be the rotational noise and exhaust flow noise from the lift fan and its drive turbine. The compressor may also be a significant noise source in the coaxial gas generator if a high tip speed is used. For remote power systems, the additional noise sources from the drive power plant must be considered. Exhaust velocities for the compressed air generators will have to be kept relatively low, which will result in a low residual thrust and a large exhaust duct. Since these power plants will most likely be oriented horizontally in the aircraft, inlet and exhaust duct acoustic treatment can be effectively used to suppress the machinery noise. However, such provisions constitute installation penalties for these systems.

If it is assumed that power plant noise can be effectively reduced to below the level of the fan noise, then the design of the lift fan must be controlled to satisfy noise limitations. According to current experience, fan rotational noises appears to be greater than fan exhaust noise for current VTOL fan designs. However, if it is further assumed for the moment that fan rotational noises can be reduced to the exhaust flow noise level, then an initial appraisal can be made of the impact of noise restrictions on fan design by analyzing the fan exhaust flow noise (i.e., the noise floor level).

Although it has not yet been conclusively confirmed, it is believed that fan exhaust flow mixing noise (low velocity jet noise) is proportional to the 8th power of the exhaust velocity. From an extrapolation of the standard jet noise correlation (SAE AIR 876) to low-velocities according to the 8th power, calculated variations of total perceived exhaust flow noise with number of lift fan engines containing both fan and turbine exhaust (velocities $V_{F}$ and $V_{T}$, respectively) were determined. Several fan stage pressure ratios, as shown by the solid curves in Fig. 9 are included. Also shown on the figure by the dashed lines are values of exhaust noise re- 
quired to meet several proposed perceived overall aircraft noise limits. The plotted values of exhaust noise limits were obtained from the consideration that with fan rotational and exhaust noise equal, the magnitude of the exhaust noise limit will be $3 \mathrm{PNdb}$ lower than the overall limit. It is seen that fan stage pressure ratios of the order of 1.15 to 1.20 are indicated, depending on the specific overall noise limit selected. However, since fans will most likely be noise rated at the normal maximum thrust point (Fig. 8), the allowable design (installed thrust) pressure ratio will be somewhat greater than the values determined by the noise limits.

In order to achieve fan noise limitations as indicated above, fan rotational perceived noise must be reduced to the level of the exhaust flow noise. The control of fan rotational noise is a complex matter because of the large number of factors that can affect the noise generation: tip speed, blade loading, flow turbulence, rotor tip flow, and blade-row geometry (number of blades, distance between rows, lean angle, etc.). Of particular importance in lift fan system design is rotor tip speed. High values of tip speed are desired to reduce the number of drive turbine stages or increase turbine efficiency for fixed number of stages. Current knowledge indicates that acoustic treatment of the fan duct will be necessary to achieve the desired reduction in rotational noise.

Research on lift fan noise at NASA Lewis Research Center is currently being directed to cover the major areas of:

(1) Experimental determination of fan exhaust flow noise floor level:

(2) Experimental investigation of relations between rotational noise and fan design

(3) Experimental evaluation of required duct acoustic treatment

(4) Analytical studies of propulsion system noise footprints during transition flight for severl lift fan system concepts and overall propulsion arrangements

A considerable increase in knowledge and control of lift fan noise is anticipated in the next year or two. 
Weight and Volume

The importance of lift fan system weight in VTOL transport design is illustrated in Fig. 10. Gross weight for a 100-passenger aircraft is plotted on the ordinate. The abscissa represents the ratio of installed thrust to weight of the lift fan system installation, which includes the dry weight of the thrusters and power plants plus the weights of the various installation components (containing pod or other mounting structure, inlets, exhaust ducts and deflectors, interconnecting duct system, and control system). Lift fan system specific fuel consumption is included as a parameter.

It is seen from the figure that aircraft gross weight tends to increase rapidly as system installed thrust-to-weight ratio is reduced, while the sensitivity to specific fuel consumption shows little variation. The calculation was made for a simplified aircraft model which included provision for crew, cargo, cabin equipment, airframe structure, and cruise propulsion and fuel.

Projected trends in lift fan system uninstalled thrust-to-weight ratio are presented in Fig. 11 together with variations for other types of engines. The available data points for lift fans are for coaxial and gas generatortip turbine systems in the thrust range of 10000 to 15000 pounds. The band presented for the lift fan system weight is the author's estimate of realistic values for fan systems in commercial use for which good maintainability and reliability are required. With indicated uninstalled thrustto-weight ratios around the 10 to 12 level, and with installation weight additions of say around 25 to 40 percent, installed lift fan system thrust-toweight ratios of the order of only 8 to 9 may be achievable. According to Fig. 10, such values will result in a relatively heavy aircraft. It would seem, therefore, that considerable attention should be given to the impact of lift system dry weight and installation weight on aircraft design. It is also clear that further reduction of installed weight is needed.

In this respect, reduction in dry lift system volume might be as important as reductions in system dry weight because of the compounding effect of volume on installation weight. For the fans, low volume is dependent on achieving high ratios of thrust/airflow and airflow/frontal area. 
Thrust/airflow is determined by fan stage pressure ratio and efficiency, and airflow/frontal area will also depend on fan pressure ratio. Fan volume might also be dictated by inlet section and acoustic treatment requirements. Low powerplant size is favored by reduced power requirement and by compact components and high turbine inlet temperature.

The importance of fan stage pressure ratio in influencing lift fan system volume and weight can be inferred from Fig. 12* Low fan pressure ratio produces a large fan diameter and volume but requires a smaller drive power plant. A somewhat lower fuel consumption also results.. The trend is reversed for high fan pressure ratios, so that for a given aircraft design and thrust level, there is probably an optimum fan pressure ratio for minimum installed system weight. However, since fan pressure ratio will be determined by noise limitations, system research effort should be directed toward minimizing component weight and volume for the selected pressure ratio levels.

Low component weight will depend on high aerodynamic loading, lightweight materials, and efficient structural design. Unlike conventional cruise engines, lift system components must be designed to satisfy cycle life criteria. Annual flight operations, for example, might involve many thousands of start-stop cycles, but only around a hundred hours of accumulated time for the lift system. It is also desirable to design critical lift system components to permit operation for a brief period of time at a significant overthrust condition (say 10 percent) during emergency "engineout" situations. As indicated earlier, an emergency overthrust rating is desirable to reduce installed thrust level. In the event of the use of the emergency rating, it is probable that inspection of sensitive system parts will be required.

*Specific values of the parameters in Fig. 12 at the reference fan pressure ratio, expressed as a ratio of fan thrust are: fan tip frontal area, $1.44 \times 10^{-3} \mathrm{ft}^{2} / \mathrm{lb}$; airflow rate, $0.0488(\mathrm{lb} / \mathrm{sec}) / \mathrm{lb}$; drive power, 0.727 $\mathrm{HP} / \mathrm{lb}$; and specific fuel consumption, $0.4(\mathrm{lb} / \mathrm{hr}) / \mathrm{lb}$. 


\section{Components}

There are a number of significant research problem areas that can be identified for lift fan system components. Some are general for all fan configurations, while others are unique to the particular fan drive concept employed. The overall importance of light-weight, low-noise generation components has been mentioned earlier. However, some study is in order to determine whether some of the fan drive concepts have a greater potential than others for utilizing advanced material and structural innovations. For example, the integral coaxial fan (Fig. 1(a)) might make better use of composite structures in the fan stage than the hot-gas tip-turbine arrangements (Figs. 1(b) and (c)) due to the low temperatures involved.

The potential for obtaining critical component designs that will allow a sizeable emergency overthrust capability without large penalty in installed characteristics warrants investigation. Also, good fan stage efficiency and inlet distortion tolerance are desired for all configurations. Control of stator and duct losses will be particularly important in view of the relatively low allowable fan pressure ratio. If low rotor tip speeds are required for noise considerations, performance problems may be encountered at the hub of the stator. This problem can be alleviated to a large extent with the integral coaxial fan through the use of a flow passage splitter (as in Fig. 2) and separate designs for the two rotor sections.

Another common factor for fans involved in the attitude control function is the thrust acceleration time response. Preliminary estimates indicate desired response times of the order of 0.3 second for a 10 to 25 percent thrust increase for a large VTOL transport. Since response time varies directly with moment of inertia of the rotating components and inversely with the accelerating torque, component size and mass will be significant factors. The largest determinant of rotating inertia is component size, since moment of inertia for a given configuration will vary with the 4th to 5 th power of the diameter. Thus, the number of fans used for given total thrust will be the most significant design control element for response time. However, for a given fan thrust level, any reduction in rotating mass will directly benefit thrust response time. 
Specific component problem areas for the different drive systems are identified as follows:

(1) Integral coaxial system

(a) Fan drive turbine - high stage loading, reduced number of stages, and support structure

(b) Core compressor - inlet distortion tolerant design, or distortion suppression devices

(c) Reverse-flow combustor - length, pressure drop, and temperature profiles

(2) Tip-turbine exhaust gas generator system

(a) Fan turbine scroll - high-temperature construction and cooling

(b) Turbine bucket and attachment - temperature gradient effects

(c) Turbine front seal - leakage effect on fan rotor

(3) Tip-turbine compressed air generator system

(a) Turbine front seal - integrity and leakage

(b) Turbine performance - short height and interstage seal and leakage

(c) Turbine structure - dimension and unbalance control

(d) Turbine scroll - high temperature construction

(e) Fan turbine combustor - length and temperature profile

(f) Air generator - reverse-flow combustor length, pressure drop, and temperature profile

(4) Hub-turbine compressed air generator system

(a) Drive turbine - number of stages, high-stage loading, and support structure

(b) Flow distribution system - outer scroll, stator-strut, and inner plenum design, and pressure drop

(c) Combustor - length and temperature profile

Analyses of component design and performance are currently being conducted at the Lewis Research Center for the major component problem areas listed above. Experimental investigations will be initiated for key component and package configurations as indicated by the results of the analyses. In addition to this specific effort on unique lift fan component problems, the general 
Center research effort on advanced gas turbine engine components in the areas of compact compressors, high-work turbines, turbine cooling, compact combustors, and bearings and seals will be directly applicable to VTOL powerplant design.

\section{System Design}

Unfortunately, the elements that favor low system weight and volume are generally inconsistent with good fuel economy, good maintainability, and high reliability characteristics. According to Fig. 10, aircraft gross weight does not appear to be highly sensitive to lift system specific fuel consumption. However, high system reliability and good overhaul and maintenance characteristics are essential for economical commercial operations. Dispatch reliability in VTOL operations will be particularly important in view of the overall complexity of the propulsion system and the large number of units and components involved. Systems based on more conventional components and configurations for which a reliability history or experience is available might therefore offer a better development risk in the long run.

In view of system complexity, rapid event occurrence, and heavy pilot work load, it is clear that an automatic control system will be required. The control system would handle normal engine operating functions (startup, check out, throttling), attitude control requirements, "engine-out" trim procedures, and possibly prescribed transition flight path control. An extremely sophisticated integrated control and propulsion system arrangement will therefore be required which will also have to have a high degree of reliability.

\section{FAN TRANSITION PERFORMANCE}

There are a number of research problem areas associated with the performance of lift fans during the transition between horizontal and vertical flight. These problems arise as a result of the orientation of the inlet of the fan with respect to the oncoming flow, the functions that the lift fan is required to perform, and the large masses of air that are set in motion by the operation of the fans. These problems, which are similar in principle to those encountered with earlier experimental VTOL lift fan aircraft, are ex- 
pected to be more severe in large VTOL transports because of the larger number of fans involved and the need for achieving optimized performance.

\section{Inflow Distortion}

A problem that was recognized in early considerations of lift fans is that of inlet flow distortion and performance loss due to the change in inflow direction during forward flight. The nature of this crossflow effect on fan inflow is illustrated in Fig. 13. Under static conditions (zero forward flight), the flow into the inlet is largely axisymmetric as indicated in Fig. 13(a). Under crossflow conditions during transition (Fig. 13(b)), an acceleration and deceleration of the flow occurs over the forward portion of the inlet, which generally leads to a local separation of the flow as indicated by the shaded area. Flow separation can also occur on the aft side of the centerbody. At the same time, the incomplete turning of the inflow into the fan passage results in an "advancing-retreating" orientation for the rotating rotor blades as indicated by the lower sketch of Fig. 13(c). The circumferential variation in approach angle in conjunction with the circumferential variation in meridional velocity (Fig. 13(b)) then produces a circumferential variation in change in incidence angle on the rotor as illustrated in the upper sketch of Fig. 13(c).

The combination of flow separation and rotor inlet flow maldistribution can result in a deterioration of fan efficiency and thrust as flight speed is increased. There is also concern that the inlet flow distortion and the increased flow turbulence due to poorer fan performance can measurably increase the fan noise radiation during transition.

Many experimental investigations of flow distributions in lift fan inlets in crossflow have been conducted in the past ${ }^{25,30}$ to 33 . Current effort at NASA is directed toward developing analytical techniques for determining inlet flow distributions and surface boundary layer development. A potential flow solution for the design and analysis of axisymmetric inlets in static flow is described in Ref. 34. Preliminary discussion and comparisons with experimental data for the comparable crossflow solution are given in Ref. 35. Boundary layer theory and experiments aimed at the prediction and control of flow separation in lift fan inlets in crossflow are being pursued on a research grant basis. 
An example of the calculated variation in surface velocity over the forward arc of a lift fan inlet in crossflow is shown in Fig. 14 for several crossflow velocities. The inlet section was originally designed for the avoidance of surface velocity deceleration under static conditions $\left(V_{\infty}=0\right)$. The sharp velocity acceleration and deceleration on the surface resulting from the crossflow is clearly seen. Calculated variations of change in incidence angle relative to the static case for a hypothetical "disturbancefree" rotor located at the inlet station ( $=0$ in Fig. 14) are illustrated in Fig. 15. ( $A{ }^{19}$ disturbance-free" ${ }^{p 1}$ rotor is one that produces no change in the upstream flow。) Significant unsymmetrical changes in rotor incidence angle may therefore occur for a real fan. However, the presence of the rotor and its pressure field will undoubtedly disturb the incoming flow to some extent, so that the net effect on the rotor operation is unknown (possibly not as severe as suggested by the idealized calculations)。

\section{Force Variations}

The aspect of fan flow during transition that has received considerable attention is the interaction of the fan flow with the flow around the aircraft. Numerous wind tunnel tests of fan-in-wing, fan-in-pod, and fan-in-fuselage configurations have been conduted 36 to 41 , and a good understanding of the effects of fan flow on aircraft induced lift, drag, and moments has been obtained (e.g., Refs. 42 to 45). A strong effort in lift-fan aircraft aerodynamics has been mounted in particular by the NASA Ames Research Center.

The basic situation with respect to aerodynamic forces during crossflow is illustrated schematically in Fig. 16. Drag contributions are provided by the fan mounting structure (e.g., wing or fuselage pod) and the ram drag of the fan inflow (flow rate times flight speed). In this respect, the lower the allowable fan pressure ratio, the higher the flow rate for a given thrust (Fig. 12) and therefore the higher the ram drag. Pod drag is determined by the geometry of the body containing the fans, the auxiliary devices for the fan (e.g., louvers, cover doors), and the interaction between the fan flow and the normal flow around the body.

For the lift and thrust forces (Fig。16), concern is over both thrust degradation and induced lift forces generated by the interaction between the 
fan flow and the flow over the aircraft aerodynamic surfaces. These induced forces can be negative or positive, depending on the number of fans and their location on the aircraft. Fan thrust degradation is measured with respect to ideal fan thrust (dashed line in Fig. 16) obtained from the conditions of no inlet total pressure loss, constant total pressure ratio across the rotor, and ambient discharge pressure. Fan discharge static pressures both below and above the ambient value can be generated by local external flow interactions and by external devices such as louvers or closure doors. Such pressure variations can alter the operating point of the fan.

Since aircraft wing lift increases with flight speed, some decrease in fan vertical thrust should be allowable as conversion speed is approached. However, the acceptable thrust degradation for an aircraft design will depend to a large extent on the transition flight profile and associated requirements for thrust magnitude and deflection. Parametric analys is of transport aircraft transition flight for various propulsion system arrangements and flight constraints would be helpful in evaluating the effect of fan transition performance on aircraft design and operation.

Even if transition flight dynamics can allow a sizeable degradation in fan thrust as flight speed is increased, is appears that it would always be desirable to press for minimum fan pressure losses in crossflow. Reduction in crossflow pressure losses will reduce fuel consumption and noise generation arising from reduced efficiency. The maintaining of good fan performance throughout the transition speed range can also provide a potential for controlled thrust reduction for noise abatement procedures.

Wind tunnel tests of a 15-in. diameter model lift fan are currently in progress at the NASA Lewis Research Center with the setup shown in Fig. 17. The fan rotor is driven by a compact two-stage turbine located within the hub of the fan. The turbine is powered by high-pressure air supplied through several struts across the fan passage. This configuration provides for a fan unit with coaxial discharge flows (as in the case of a real fan) that can be installed completely within the supporting aerodynamic body. Measurement is made of wing lift, drag, and pitching moment, and 
of fan performance, internal flow distributions, and axial force. Maximum tunnel air speed is $175 \mathrm{mph}$. The purpose of these initial tests is to investigate in detail the flow and force distributions generated by the fan flow in crossflow and to determine the nature and magnitude of the factors influencing thrust variation. A subsequent setup will contain a fan-in-pod arrangement for tests of performance and distortion tolerance of fan configurations involving low noise features. Variables that can be considered include rotor tip speed, rotor aspect ratio, inlet design, separation control schemes, and devices for producing favorable pressure differential for inflight starting.

Experiments are also needed to investigated tandem fan performance and flow interactions in several multiple-fan pod configurations. Concern here is for variations in fan inflow rate and performance with fan location, with spacing between fans, and with bounding surfaces. Thrust deflecting approaches as illustrated in Fig. 7 should also be included.

\section{CONCLUDING REMARKS}

If simplicity is the key to high reliability, high performance, and low cost, it appears that the development of acceptable VTOL propulsion systems for commercial applications is not exactly starting from a position of advantage. Considerable trade-off evaluations, compromises, and development effort will undoubtedly be required in lift system design. Although many, VTOL propulsion problems are not considered insurmountable. In this respect, it should be recognized that the current identification of propulsion problem areas is basically qualitative. Such qualitative evaluations may tend to generate undue concern because of the absence of quantitative data. It is quite likely that as actual research and technology efforts are accelerated, many of the current concerns may be dissipated.

A well-defined and well-integrated lift fan propulsion research effort can do much to enhance the early development of civil VTOL transports. In particular, research and analysis are needed to determine the relative importance of the various problem areas - which factors have a large or small impact on overall design and performance - and to provide quantitative data for the key input factors that will be involved in system selection 
and design. The traditional role of research in devising new concepts and solving specific problems will also be helpful.

It is expected that the next few years will witness a clearer direction and a resolution of the more difficult aspects of propulsion design for VTOL transport aircraft.

\section{REFERENCES}

1. Brown, D. G., "The Case for V/STOL Aircraft in Short-Haul Transportation, " Paper 700333, Apr. 1970, SAE, New York, N. Y.

2. Jagger, D. H. and Kemp, E. D. G., "The Potential and Development of a V/STOL Inter-City Airliner, " Aircraft Engineering, vol。42, no. $1,1970, \mathrm{pp}$. 6-13.

3. Simpson, R. W., "The Outlook for Future Commercial VTOL Transportation," Paper 69-198, Feb. 1969, AIAA, New York, N.Y.

4. Asher, N. J., "Demand for Intercity Passenger Transportation by VTOL Aircraft," Journal of Aircraft, vol。6, no. 5, Sept.-Oct. 1969 , pp. $452-456$.

5. Stultz, J. T. and Dorozenski, R。W., "V/STOL Considerations in Air Traffic Control," Paper 69-1055, Oct.1969, AIAA, New York, N. Y.

6. Hayward, D. W., "Study of Aircraft in Short-Haul Transportation Systems for 1985," Paper 67-771, Oct.1967, AIAA, New York, N. Y.

7. Howard, L. R。, "Overall Analys is of Commercial V/STOL Systems, " Paper 67-969, Oct. 1967, AIAA, New York, N.Y.

8. Deckert, W. H. and Hickey, D. H., " Feasibility-Study Designs of V/STOL Transport Aircraft, $"$ Journal of Aircraft, vol。7, no.1, Jan.-Feb.1970, pp.66-72.

9. Anon., "V/STOL Transports Under Study by Lufthansa, German AF," Vertical World, vol.5, no.1, Jan.-Feb.1970, pp. 14-17. 
10. Hill, T.G., "An All Turbofan VTOL or STOL Intercity Transport," Paper 69-1039, Oct. 1969, AIAA, New York, N. Y.

11. Kappus, P. G., "Design Concept for a V/STOL Intercity Jet," Paper 69-200, Feb.1969, AIAA, New York, N.Y.

12. Posner, D. L., "Commercial VTOL Transport Design, Operation and Economics," Paper 67-970, Oct. 1967, AIAA, New York, N.Y.

13. Coty, U. A. and Kesling, P. H., "V/STOL and STOL for Short-Haul Transportation'," Paper 67-941, Oct. 1967, AIAA, New York, N.Y.

14. West, R. G., "Fan Lift in VTOL Design," Aeronautical Journal, vel. 73, no. 704, Aug. 1969, pp. 657-664.

15. Wilde, G. L. , "Engines for VTOL/STOL Application," Annals of the New York Academy of Sciences, vol. 154, art. 2, Nov. 1968, pp. 590-618.

16. Coplin, J. F., "Design Aspects of Power Plants for V/STOL Aircraft," Paper 67-GT-7, Mar. 1967, ASME, New York, N.Y.

17. Davies, D. O.. and Coplin, J. F., "Some VTOL Powerplant Design and Development Experience," Journal of the Royal Aeronautical Society, vol. 70, no. 671, Nov. 1966, pp. 977-986.

18. Wilde, G. L. and Coplin, J. F., "Lift Turbo-fans," Journal of the Royal Aeronautical Society, vol. 69, no. 656, Aug. 1965, pp. 553-566.

19. Pickerell, D. J. and Cresswell, R. A., "Powerplant Aspects of HighSpeed, Inter-City VTOL Air craft," Journal of Aircraft, vol. 5, no. 5, Sept.-Oct. 1968, pp. 467-472.

20. Sens, W. H. and Meyers, R. W., "New Generation Engines - The Engine Manufacturer's Outlook," Paper 680278, Apr. 1968, SAE, New York, N.Y..

21. Asmus, F。 J., "Design and Development of the Tip Turbine Lift Fan," Annals of the New York Academy of Sciences, vol. 107, art. 1, 1963, pp. 147-176. 
22. Kutney, J. T., "Propulsion System Development for V/STOL Transports," Journal of Aircraft, vol. 3, no. 6, Nov. -Dec. 1966, pp. 489-497.

23. True, H. C., "The Turbotip Lift Fan VTOL Propulsion System - After the First Generation," Paper 115, May 1967, American Helicopter Society, New York, N.Y.

24. Przedpelski, Z。 J., "Lift Fan Technology Studies," CR-761, 1967, NASA, Washington, D.C.

25. Beeler, E. F。 and Przedpelski, Z. J., "Lift Fan Design Considerations," Annals of the New York Academy of Sciences, vol. 154, art. 2, Nov. 1968, pp. 619-640。

26. Volk, L。 J., "LF-336A High Pressure Ratio Lift Fans, " R69AEG180, NASA CR-73387, Apr. 1, 1969, General Electric Co., Cincinnati, Ohio.

27. Immens chuh, W. T., "XV-5A-A Lift Fan V/STOL Research Aircraft," Verti-Flite, vol. 11, May 1965, pp. 2-9.

28. Beeler, E. F. and Volk, L. J., "Lift Fan Propulsion Systems - V/STOL Aircraft Control," Paper 650831, Oct. 1965, SAE, New York, N.Y.

29. Stadler, J. P., "The Attitude Control System as an Integral Part of the V/STOL Propulsion System Installation," Paper 70-GT-31, May 1970, ASME, New York, N.Y.

30. Schaub, U. W. , "Experimental Investigation of Flow Distortion in Fan-inWing Inlets," Journal of Aircraft, vol. 5, nọ. 5, Sept. -Oct. 1968, pp. 473-478.

31. Gregory, N., Raymer, W. G., and Love, E. M., "The Effect of Forward Speed on the Inlet Flow Distribution and Performance of a Lifting Fan Installed in a Wing, " R \& M-3388, 1965, Aeronautical Research Council, Great Britain, 1965.

32. Schaub, U. W. and Bassett, R. W., "Analys is of the Performance of a Highly Loaded 12-Inch VTOL Z-Axis, Fan-in-Wing Model at Zero Forward Speed," LR-439, Sept. 1965, National Research Council of Canada, Ottawa, Ont. 
33. Fowler, H. S. , "Some Tests of 12-Inch-Diameter Model VTOL Fans," LR-367, Feb. 1962, National Research Council of Canada, Ottawa, Ontario.

34. Stockman, N. O. and Lieblein, S., "Theoretical Analysis of Flow in VTOL Lift Fan Inlets Without Crossflow," TN D-5065, 1969, NASA, Cleveland, Ohio.

35. Stockman, N. O., "Potential Flow Solutions for Inlets of VTOL Lift Fans and Engines," Analytic Methods in Aircraft Aerodynamics, SP-228, 1969, NASA, Washington, D.C., pp. 659-681.

36. Hickey, D. Ho and Hall, L. P., "Aerodynamic Characteristics of a Large-Scale Model with Two High Disk-Loading Fans Mounted in the Wing," TN D1650, 1963, NASA, Moffett Field, Calif.

37. Kirk, J. V., Hickey, D. H., and Hall, L. P., "Aerodynamic Characteristics of a Full-Scale Fan-in-Wing Model Including Results in Ground Effect with Nose-Fan Pitch Control, " TN D-2368, 1964, NASA, Moffett Field, Calif.

38. Hickey, D. H., Kirk, J. V., and Hall, L. P., "Aerodynamic Characteristics of a V/STOL Transport Model with Lift and Lift-Cruise Fan Power Plants," Conference on V/STOL and STOL Aircraft, SP-116, 1966, NASA, Washington, D.C.o, pp. 81-96.

39. Turner, R. C. and Sparkes, D.W., "Tests on a Simulated Lifting Fan System with Inlet Crossflow, " R \& M 3461, 1964, Aeronautical Research Council, Great Britain.

40. Hackett, J. E., "Wind Tunnel Tests on a Streamlined Fan-Lift Nacelle, " R \& M 3470, 1965, Aeronautical Research Council, Great Britain.

41. Gregory, N. and Love, E. M., "Wind Tunnel Tests on a Nacelle Fitted with Two Lifting Fans in Tandem, " R \& M 3494, 1966, Aeronautical Research Council, Great Britain.

42. Goldsmith, R。H. and Hickey, D. H., "Characteristics of Lifting-Fan V/STOL Aircraft," Astronautics and Aerospace Engineering, vol。1, no. 9, Oct. 1963, pp.70-77. 
43. Hickey, D. H. and Cook, W. L., "Aerodynamics of V/STOL Aircraft Powered by Lift Fans," Fluid Dynamics of Rotor and Fan Supported Aircraft at Subsonic Speeds, CP No. 22, Sept. 1967, Advisory Group for Aerospace Research and Development, Paris, France, Paper No. 15.

44. James, H. A., "Generalized Characteristics of Vertifan Aircraft in the Fan Mode," Annals of the New York Academy of Sciences, vol. 154, art. 2, Nov。1968, p. 196.

45. McKinney, M. O. and Newsom, W. A。, "Fan V/STOL Aircraft," Annals of the New York Academy of Sciences, vol.154, art. 2, Nov. 1968, pp. 872-892. 


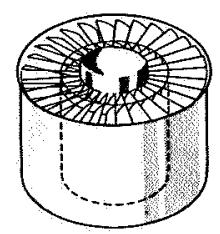

(A) HUB TURBINE WITH INTEGRAL COAXIAL GENERATOR.

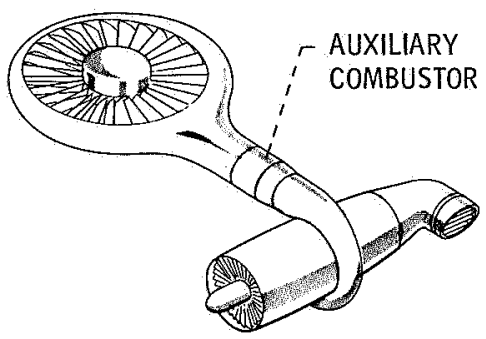

(C) TIP TURBINE WITH REMOTE COMPRESSED AIR GENERATOR.

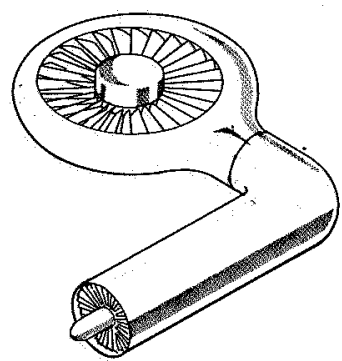

(B) TIP TURBINE WITH REMOTE EXHAUST GAS GENERATOR.

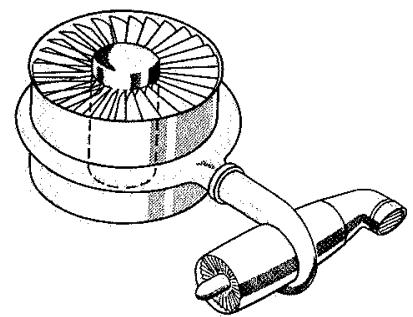

(D) HUB TURBINE WITH REMOTE COMPRESSED AIR GENERATOR.

Figure 1. - Lift fan drive system concepts.

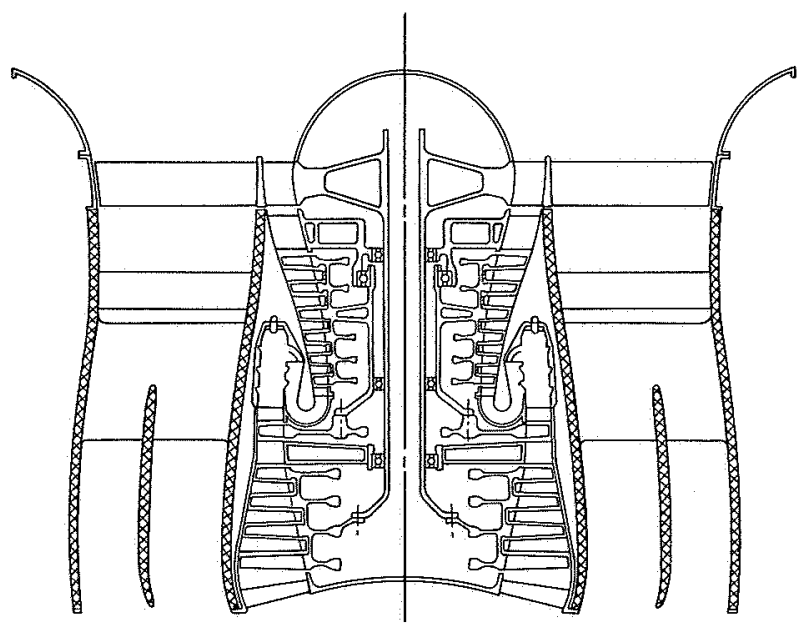

Figure 2. - Integral coaxial lift fan system. 

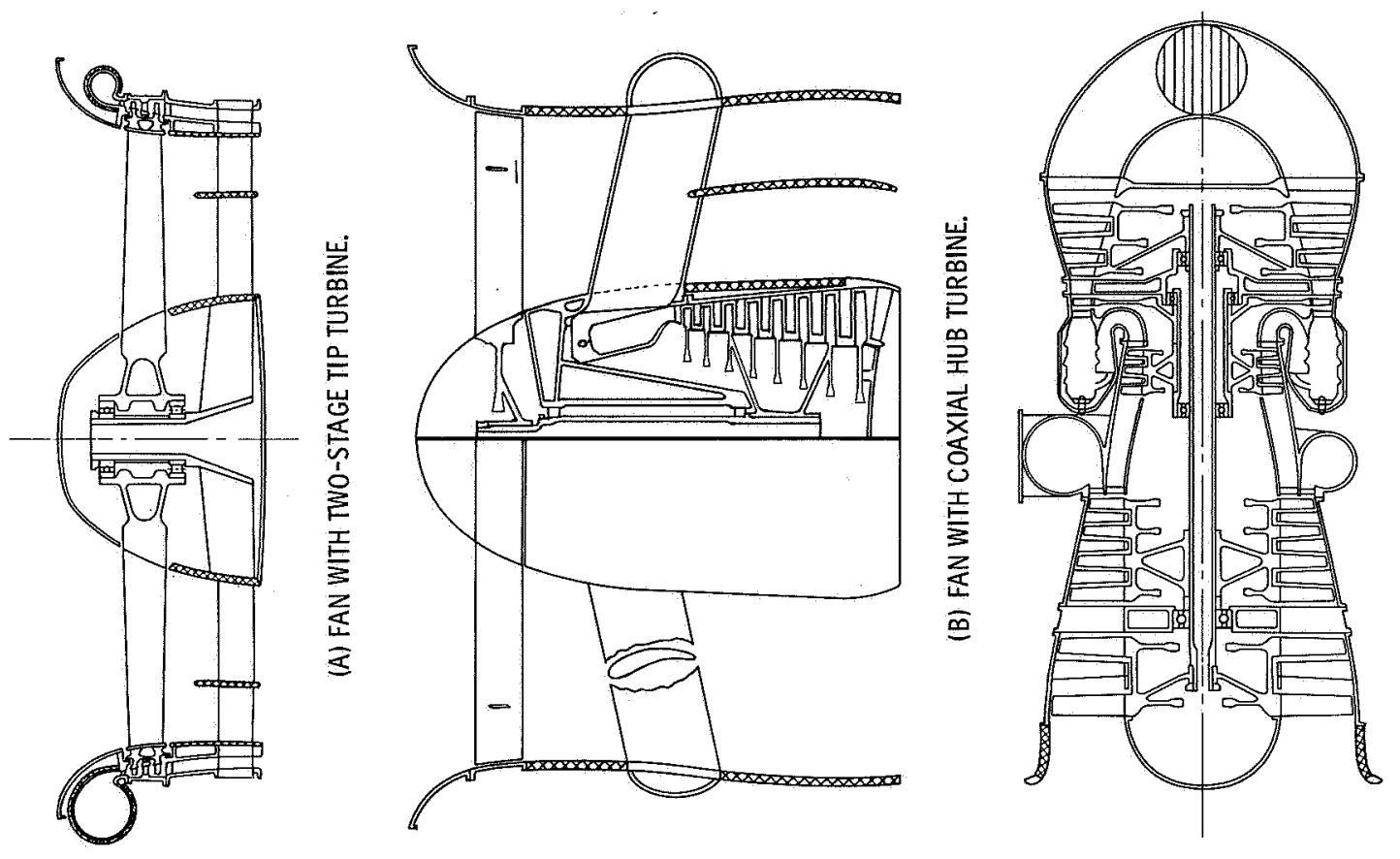

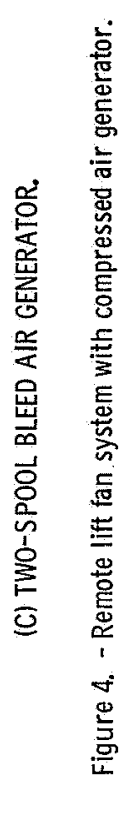

四

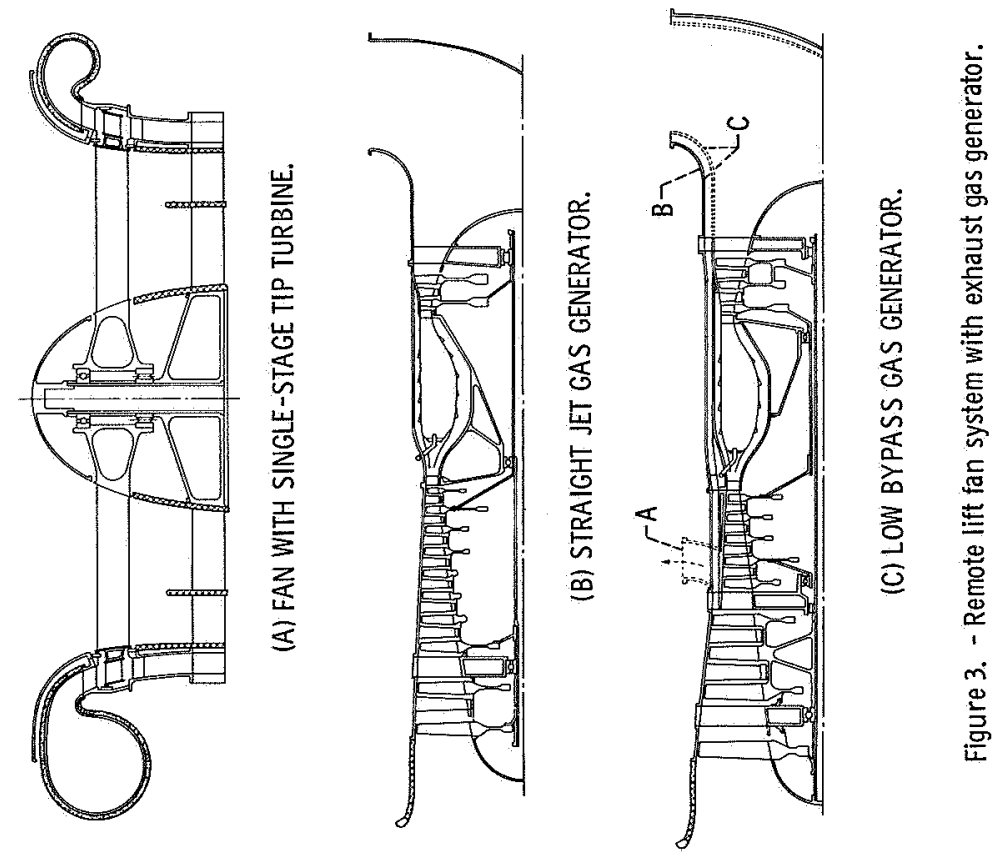


+
6
6
1
1

\begin{tabular}{|c|c|c|c|}
\hline INTEGRAL & TIP TURBINE-GAS GENERATOR & TIP TURBINE-AIR GENERATOR & HUB TURBINE-AIR GENERATOR \\
\hline $\begin{array}{l}\text { SINGLE INDEPENDENT UNITS } \\
\text { CAN SWIVEL } \\
\text { OVERTEMPERATURE MARGIN }\end{array}$ & $\begin{array}{l}\text { SHORT FAN DEPTH } \\
\text { CAN INTERCONNECT* } \\
\text { AVALABLE GAS GENERATOR } \\
\text { TECHNOLOGY }\end{array}$ & $\begin{array}{l}\text { SHORT FAN DEPTH } \\
\text { CAN INTERCENNECT" } \\
\text { SMALL DIAM. SCROLL } \\
\text { SUPPLY TEMP. CONTROL } \\
\text { COLD, SMALL DIAM. DUCT } \\
\text { ADDITIONAL THRUST FROM } \\
\text { AIR GENERATOR }\end{array}$ & $\begin{array}{l}\text { CAN INTERCONNECT* } \\
\text { HIGH FAN TURBINE TEMPER- } \\
\text { ATURE } \\
\text { CONVENTIONAL DRIVE TURBINE } \\
\text { COLD, SMALL DIAM. DUCT } \\
\text { ADDITIONAL THRUST FROM } \\
\text { AIR GENERATOR }\end{array}$ \\
\hline $\begin{array}{l}\text { LONG AXIAL DEPTH } \\
\text { MANY FAN TURBINE STAGES } \\
\text { COMPRESSOR INFLOW } \\
\text { DISTORTION } \\
\text { DEVELOP POWERPLANT }\end{array}$ & $\begin{array}{l}\text { SCROLL DESIGN (HIGH- } \\
\text { TEMPERATURE COOLING) } \\
\text { LARGE DIAMETER SCROLL } \\
\text { LARGE DIAMETER, HIGH- } \\
\text { TEMPERATURE DUCT } \\
\text { OVERTEMPERATURE LIMIT }\end{array}$ & $\begin{array}{l}\text { SHORT FAN TURBINE BLADE } \\
\text { HEIGHT } \\
\text { TWO FUEL CONTROLS } \\
\text { MANY COMPONENTS } \\
\text { DEVELOP POWERPLANT }\end{array}$ & $\begin{array}{l}\text { LONG AXIAL DEPTH } \\
\text { MANY FAN TURBBINE STAGES } \\
\text { MANY COMPONENTS } \\
\text { TWO FUEL CONTROLS } \\
\text { AIR SUPPLY SCROLLS } \\
\text { DEVELOP POWERPLANT }\end{array}$ \\
\hline
\end{tabular}

"REQUIRES VALVES AND CONTROLS

Figure 5. - Lift fan system features. 


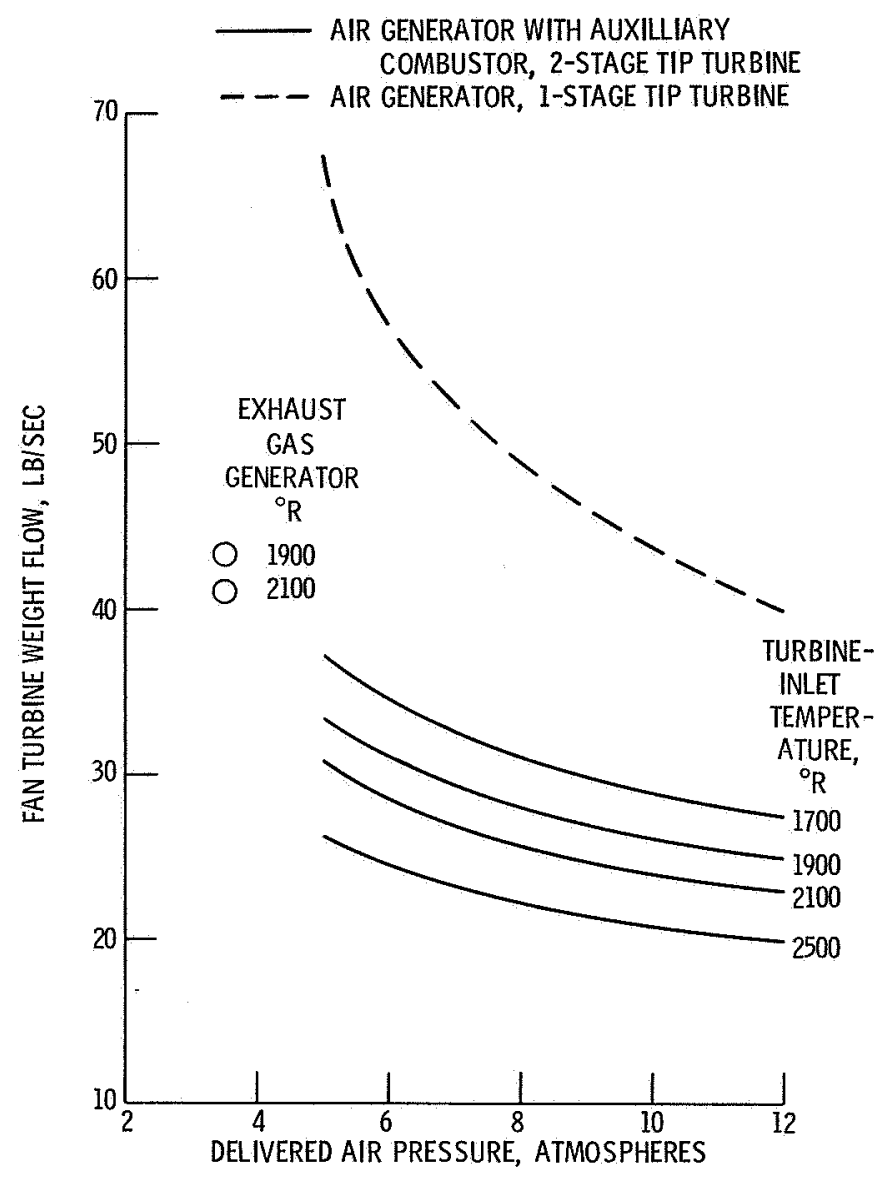

(A) REQUIRED FAN TURBINE FLOW RATE FOR TIP-TURBINE FAN. TOTAL FAN THRUST, 10000 LBS; FAN PRESSURE RATIO, 1. 20; FAN TIP SPEED, 815 FTISEC.

Figure 6. - Characteristics of remote compressed air generator systems.

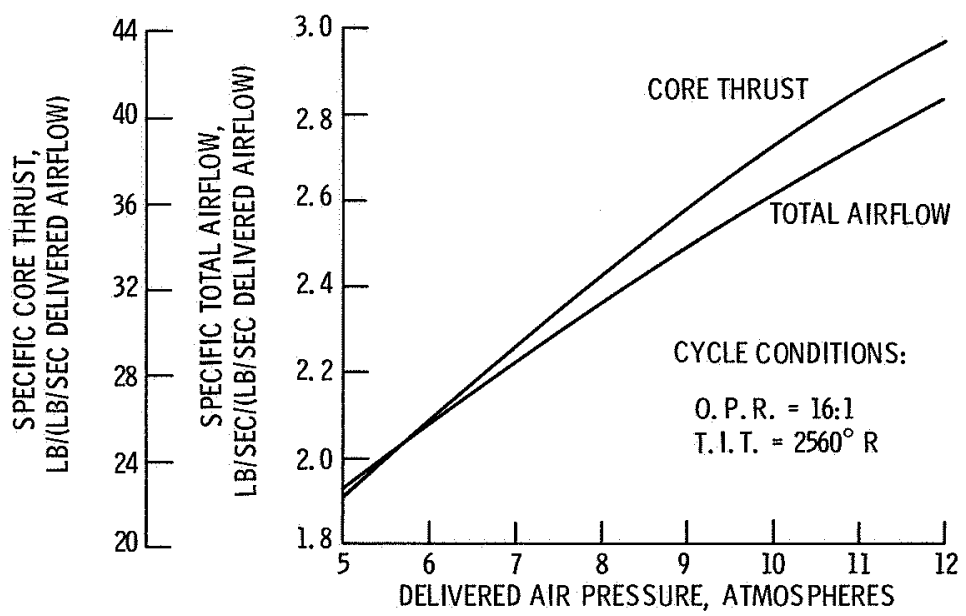

(B) AIR GENERATOR TOTAL INLET AIRFLOW AND EXHAUST THRUST.

Figure 6. - Concluded. 


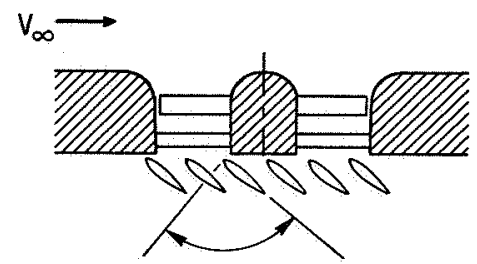

(A) LIFT FANS WITH EXIT LOUVERS.

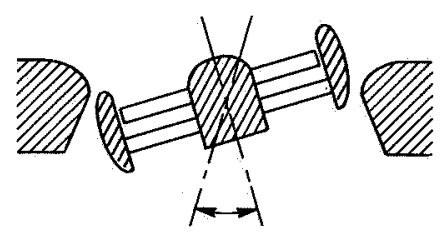

(B) SWIVELLING LIFT FAN.

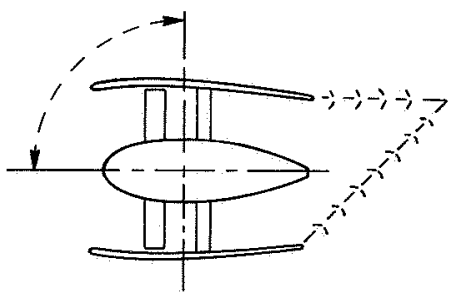

(C) FIXED CRUISE FAN WITH THRUST DE-

FLECTING AND REVERSING; OR TILTING CRUISE FAN.

Figure 7. - Methods of providing horizontal thrust for transition flight.

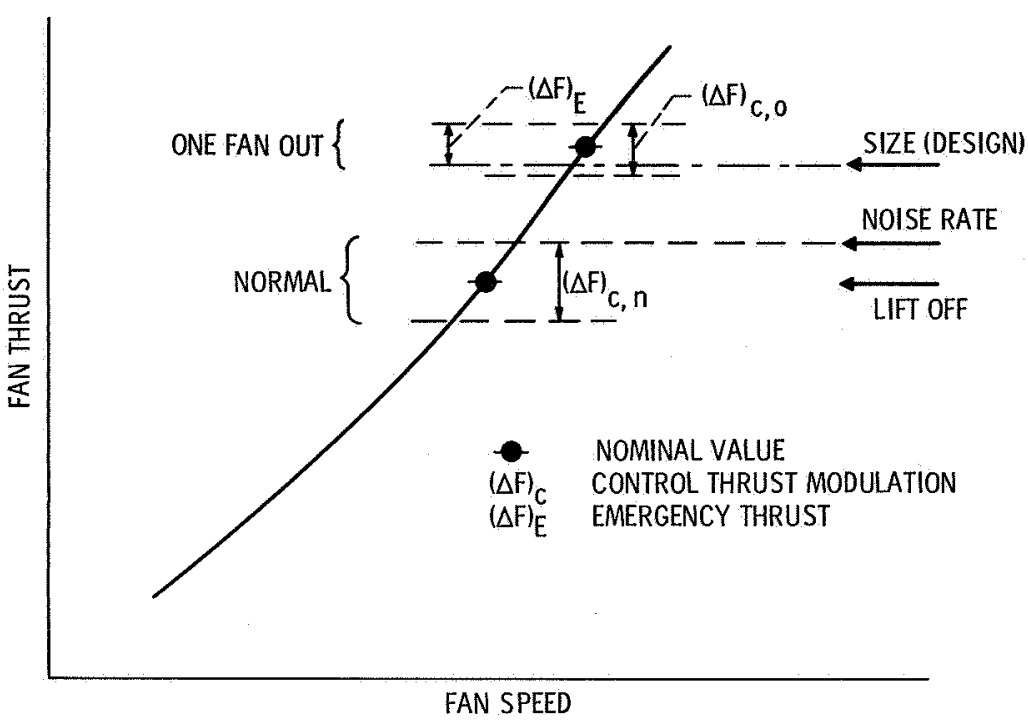

Figure 8. - Illustration of fan operating points for multifan VTOL transport; hot-day, high-altitude.

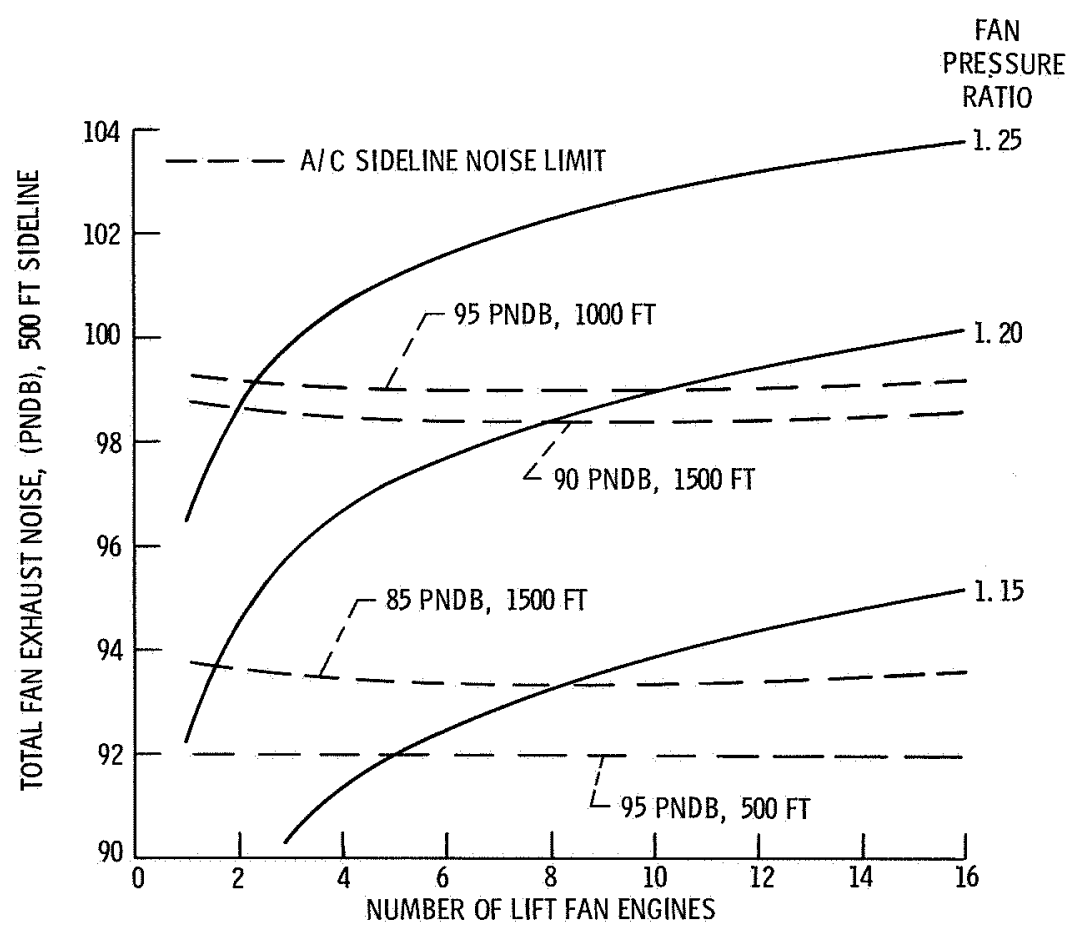

Figure 9. - Lift fan exhaust flow noise. Hub-drive lift fan engines with $\mathrm{V}_{\mathrm{T}} / \mathrm{V}_{\mathrm{F}}=1.2 ; \mathrm{V}^{8}$ jet noise model with $\mathrm{V}_{\infty}=0 ; 100000 \mathrm{lb}$ total thrust. 


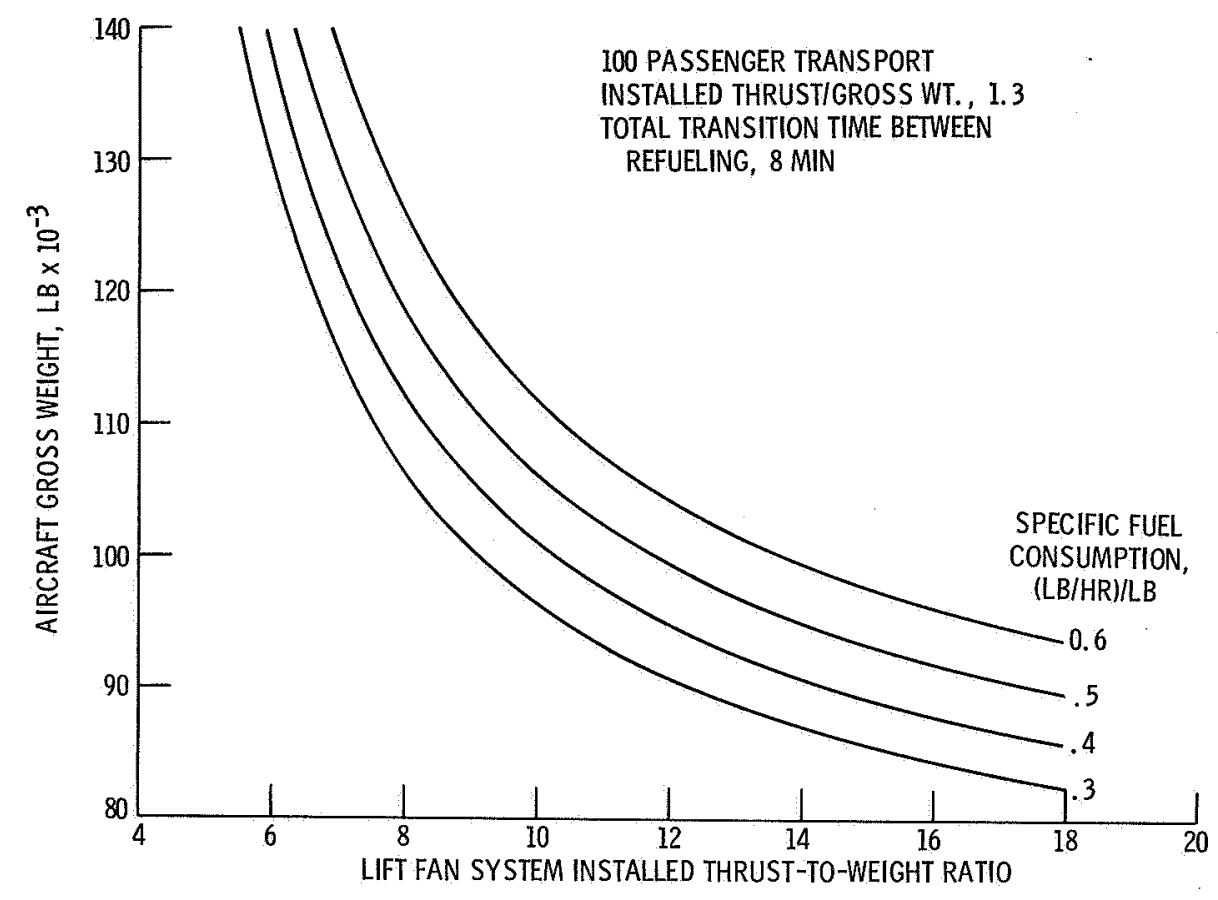

Figure 10. - Effect of lift fan system installed thrust-to-weight on airplane gross weight.

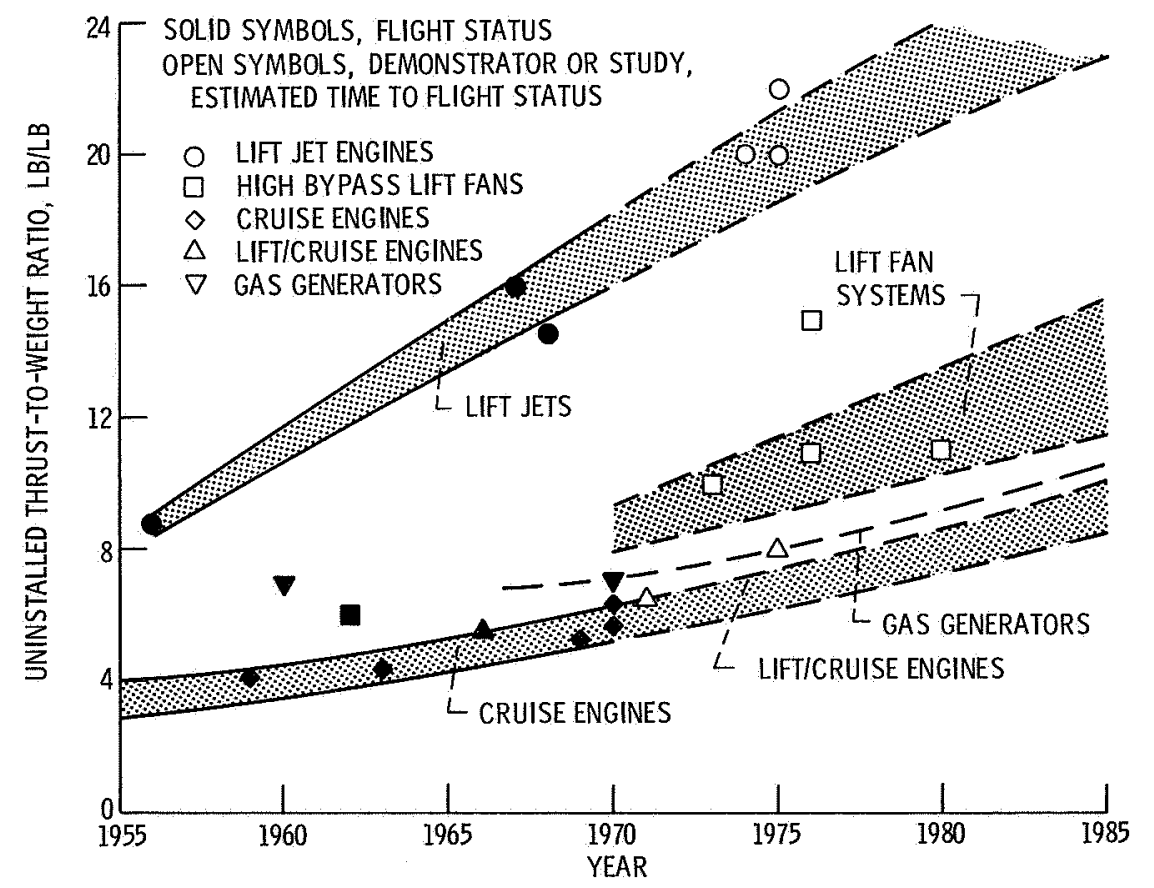

Figure 11. - Trends in engine uninstalled thrust-to-weight. 


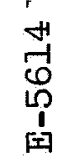
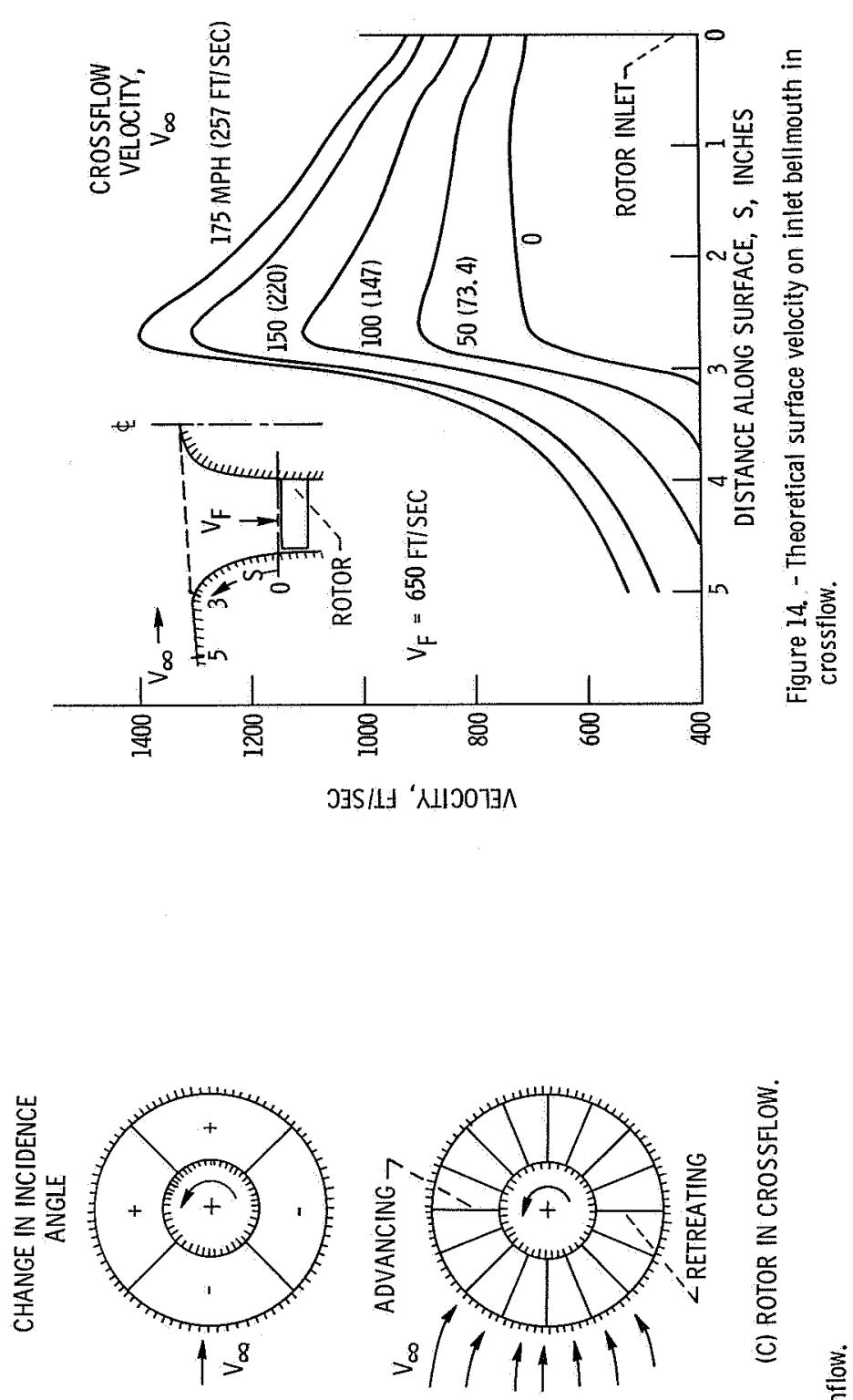

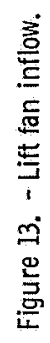




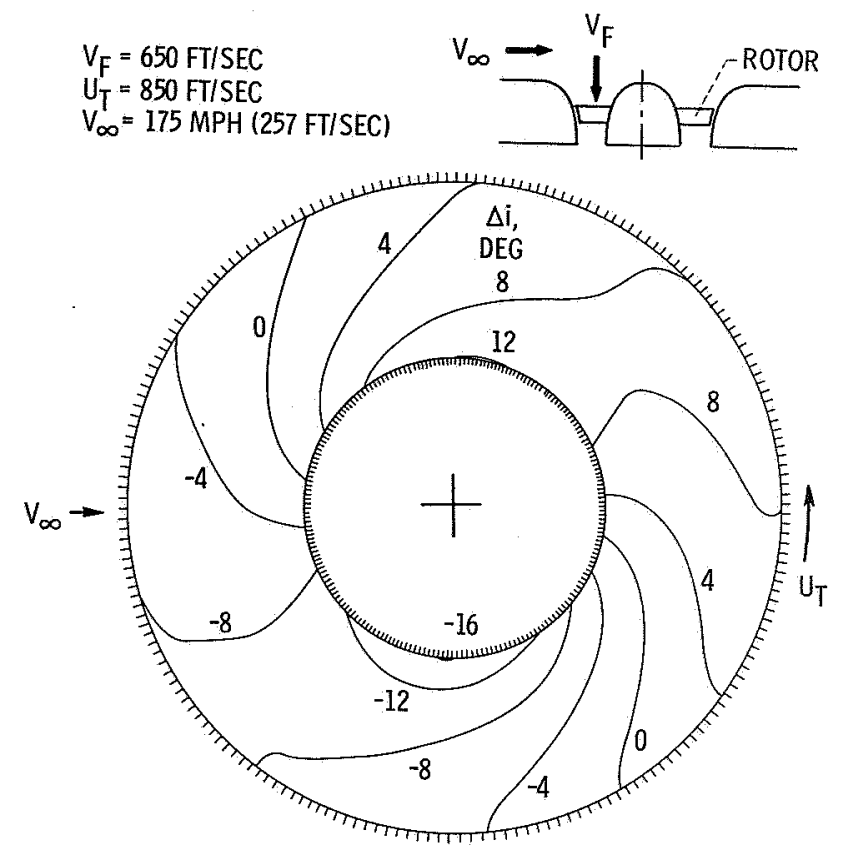

th
in
in

Figure 15. - Theoretical change in rotor incidence angle due to crossflow.

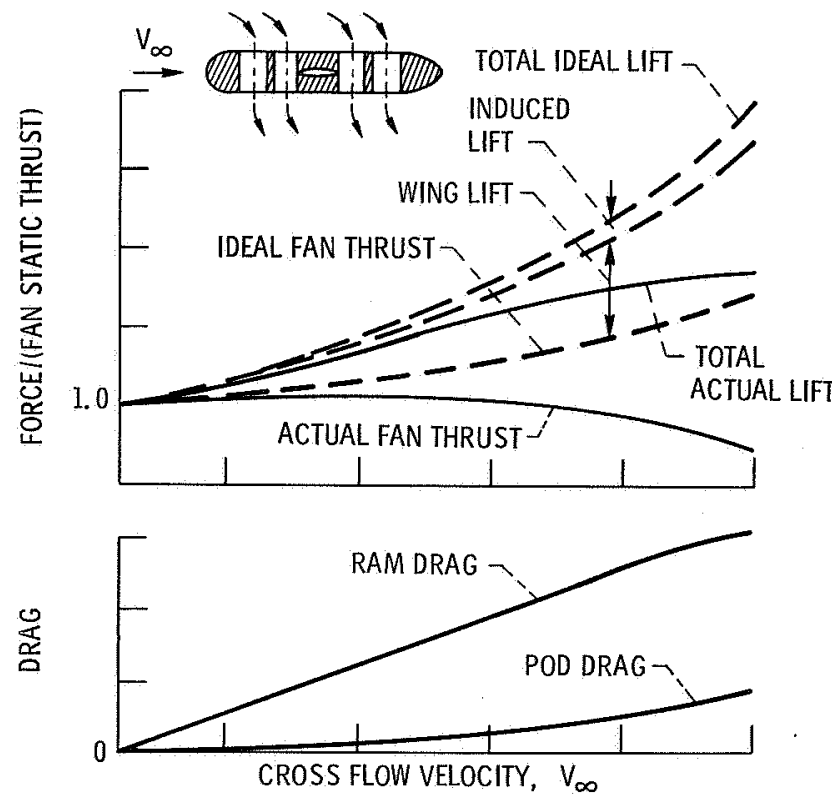

Figure 16. - Force variations in cross flow.

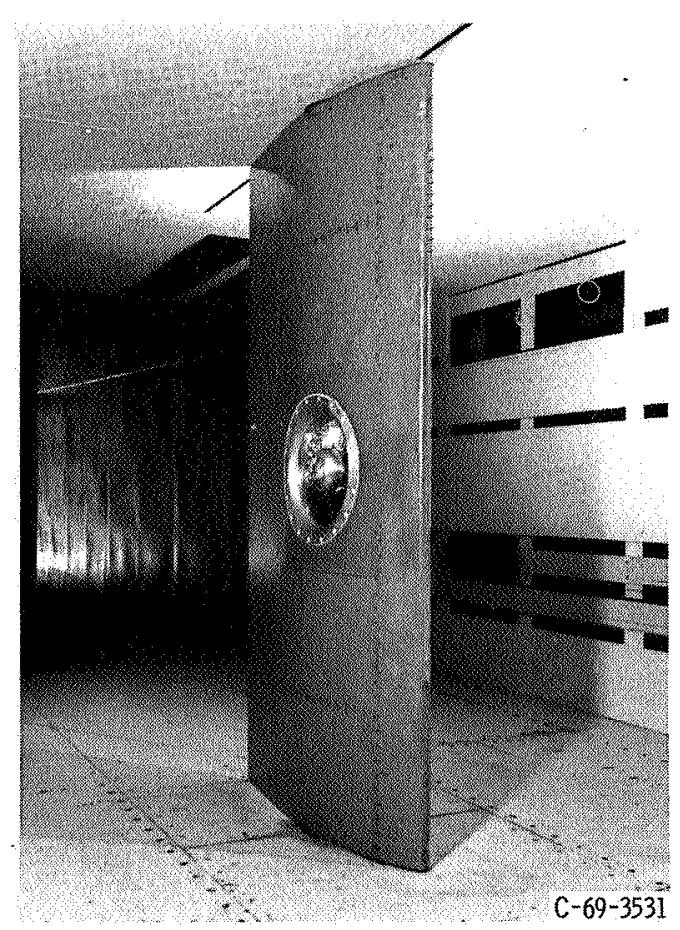

Figure 17. - Model lift fan-in-wing in Lewis Research Center V/STOL tunnel. 